$\underline{\text { Research Article }}$

\title{
The long-term challenges faced by stroke survivors and their caregivers following a stroke in Bangladesh: a qualitative study
}

Emma C Garrett-Jones, Echezona A Anakor, Firoz A Mamin, Ummul K Fatema, Shazal K Das

Keywords: global health

https://doi.org/10.29392/joghr.3.e2019053

\section{Journal of Global Health Reports}

Vol. 3, 2019

\begin{abstract}
Background
Strokes result in devastating consequences to both the survivors and caregivers, therefore it is important that it is appropriately managed and caregivers are well supported. In order to do this effectively, we need a better understanding of the challenges faced by stroke survivors and their caregivers, in a country with limited provisions for rehabilitation. Our aim was to explore the experiences of stroke survivors and their caregivers' 1-year post discharge from stroke rehabilitation in Bangladesh.
\end{abstract}

\section{Methods}

Twenty stroke survivors and their caregivers were selected for our qualitative, single-centred study. Participants were chosen using a convenience sampling method. A semi-structured questionnaire was used to collect data during face-to-face interviews. Six themes were deciphered following analysis of the data collected.

\section{Results}

There was a low return to work rate and poor awareness of stroke and its risk factors. There was no provision of rehabilitation whilst in hospital or at home and a lack of advice on how to access rehabilitation after hospital. Stroke survivors and caregivers' experienced physical, social and emotional wellbeing challenges.

\section{Conclusions}

Schemes to increase the awareness of stroke and its risk factors are needed to reduce the incidence of stroke. Earlier access to rehabilitation and ongoing support and training through implementation of a stroke pathway may improve outcomes for stroke survivors and caregivers. Future research should investigate the challenges of returning to work and the experiences of stroke survivors and caregivers who did not receive rehabilitation.

Stroke is the second leading cause of death ${ }^{1}$ and third leading cause of disability ${ }^{2}$ worldwide. In 2013 it resulted in 6.5 million deaths and 113 million disability adjusted life years. ${ }^{3}$ Asia holds $60 \%$ of the world's population, it is expected that as the control of infectious diseases improves in South Asia life expectancy will increase. ${ }^{4}$ This may result in a higher exposure to risk factors associated with stroke and therefore a higher incidence of stroke, especially if modifiable risk factors are not managed. Limited availability of healthcare in countries such as Bangladesh may result in higher mortality rates and greater numbers of disabled survivors. $^{4}$

In addition to the physical impairments caused by a stroke, the emotional, social and economic impacts of the stroke can be overwhelming for stroke survivors and their families. ${ }^{5}$ Post-stroke depression is thought to affect about one third of people with chronic stroke, it is difficult to diagnose and therefore remains unrecognised and undertreated. ${ }^{6}$ Post-stroke depression, along with factors such as social isolation, age and decreased function has been asso- ciated with a reduction in participation. 7,8 The majority of stroke survivors living at home 6 months after stroke reported a lack of social, recreational and meaningful activity. ${ }^{9}$

Balancing the dual responsibility of caring for the stroke survivor, whilst maintaining the necessary adjustments in their lifestyle, is challenging for caregivers. ${ }^{10}$ Therefore it is also critical to consider the effects of a stroke on the caregiver, especially given the sudden onset and the unexpected lifestyle changes required to adapt to this situation. Understandably, this can result in chronic stress, compromising the caregiver's physical health, ${ }^{11}$ subjective well-being and self-efficacy. ${ }^{12}$

While the effects of strokes on survivors and caregivers have been well documented, little is known about how these findings compare to a Bangladeshi population given the limited provision of rehabilitation services available to stroke survivors. ${ }^{13}$ Therefore the aim of this study is to explore the experiences of stroke survivors and their care- 
givers 1-year post discharge from stroke rehabilitation in Bangladesh.

\section{METHODS}

A qualitative study design was selected to develop a greater understanding of the experiences of stroke survivors and their caregivers. Ethical approval (CRP-BHPI/IRB/10/18/ 1252) was obtained from the Institutional Review Board, at the Bangladesh Health Professions Institute (an academic institute of Centre for the Rehabilitation of the Paralysed (CRP)). Participants were informed about the study and its aims. Informed written consent was gained prior to commencing interviews through the provision of verbal and written information in Bengali.

\section{PARTICIPANTS}

Stroke survivors and caregivers who were attending the CRP for a routine follow-up, 1 year post discharge from their rehabilitation were considered for the study. A period of 1-year post discharge from rehabilitation was selected to identify long-term challenges faced by stroke survivors and their caregivers when reintegrating into the community, thereby identifying potential unmet rehabilitation and social needs when returning home. Only patients who completed their rehabilitation at CRP were included in the study. This ensured that they had received input from qualified therapists from one of the only centres in Bangladesh where stroke survivors can access an integrated rehabilitative service encompassing Physiotherapy, Occupational Therapy and Speech and Language Therapy. ${ }^{14}$

To be included in the study, patients must have a confirmed diagnosis of stroke by a registered Doctor, this was necessary due to the number of unqualified people practising medicine in Bangladesh. This would ensure that an accurate diagnosis had been made by a qualified medical professional. One of the objectives of the study was to gather information from the caregivers, therefore the caregivers had to be present at the follow-up to provide this information.

Patients were excluded if they had a previous history of stroke, surgery for stroke or a Transient Ischaemic Attack. Patients with severe communication or cognitive impairments were excluded due to the subjective nature of the study.

\section{DATA COLLECTION}

The sample population was selected using the convenience sampling method. A small number of participants were appropriate for our qualitative study, of those, twenty participants were sufficient to reach data saturation point.

Data was collected between $31^{\text {st }}$ March 2018 and $30^{\text {th }}$ May 2018 from participants who attended a follow-up stroke rehabilitation session at CRP, Savar, Bangladesh. CRP is one of the few providers of stroke rehabilitation in Bangladesh. ${ }^{13}$

A semi-structured questionnaire was developed to guide the researchers in their data collection during the interview. Five participants previously piloted this questionnaire. All socio-demographic information was collected and questionnaires completed during face-to-face interviews at CRP led by a final year physiotherapy student supported by their academic supervisor. All interviews were carried out in Bengali and recorded on audiotape. Interviews lasted approximately thirty minutes and no repeat interviews were conducted. Data was stored in the form of transcripts and voice recordings; any patient identifiable information was kept safe in a locked office.

\section{DATA ANALYSIS}

Three data coders manually reviewed the transcripts and a qualitative content analysis was conducted to verify the data and decipher common themes. Information was then translated into English. The transcripts were not returned to participants for comments and the participants did not provide feedback on the findings. The researchers did not provide treatments or have any prior relationship to the participants.

\section{RESULTS}

Of the twenty-five stroke survivors and caregivers approached, twenty consented to this study and completed their interview. The majority of our stroke survivors were male (65\%), employed (70\%) and had some form of education, with only $5 \%$ having received no formal education. Each stroke survivor had a caregiver who supported them at home with various daily tasks. The caregivers were aged between 16 and 75 years old and most were female (70\%). (See Table 1 for socio-demographic details).

Six themes were deciphered following analysis of the data collected.

\section{THEME 1: PRIOR KNOWLEDGE OF STROKE}

Despite the majority having some form of education, only one stroke survivor reported prior knowledge of stroke and its associated risk factors.

"I know that hypertension, depression, fatty food, heart attack can cause a stroke.” (35-year-old female)

All stroke survivors were unaware they had had a stroke until this diagnosis was confirmed by a doctor.

\section{THEME 2: HOSPITALISATION POST STROKE}

All stroke survivors attended hospital after their stroke. Length of Stay (LOS) in hospital varied from 1 to 30 days. Stroke survivors were asked about their experiences in hospital.

“... I was just lying in bed. During my stay, about 16
days, I did not move myself out of bed. I did everything
in bed. I slept a lot. I was just on medication. I did not
receive any rehabilitation services.” (90-year-old male)

None of the stroke survivors received rehabilitation (Physiotherapy, Occupational Therapy or Speech and Language Therapy) during their hospital admission. 55\% reported no improvement in their physical, psychological or 
Table 1. Patient and caregiver socio-demographic details

\begin{tabular}{lcc}
\hline & Patients & Caregivers \\
\hline Age: & & $6(30 \%)$ \\
$11-30$ & $0(0 \%)$ & $8(40 \%)$ \\
$31-50$ & $11(55 \%)$ & $4(20 \%)$ \\
$51-70$ & $7(35 \%)$ & $2(10 \%)$ \\
$71-90$ & $2(10 \%)$ & $6(30 \%)$ \\
Gender: & & $14(70 \%)$ \\
Male & $13(65 \%)$ & \\
Female & $7(35 \%)$ & $10(50 \%)$ \\
Occupation: & & $0(0 \%)$ \\
Homemaker & $6(30 \%)$ & $9(45 \%)$ \\
Self-Employed & $2(10 \%)$ & $1(5 \%)$ \\
Employed (Public and Private Sector) & $12(60 \%)$ & $2(10 \%)$ \\
Student & $0(0 \%)$ & $12(60 \%)$ \\
Educational status: & & $2(10 \%)$ \\
No formal education & $1(5 \%)$ & $4(20 \%)$ \\
Up to Secondary School Certificate & $10(50 \%)$ & $3(15 \%)$ \\
Higher School Certificate & $6(30 \%)$ & \\
Bachelor degree and above & & \\
\hline
\end{tabular}

social wellbeing whilst in hospital, whereas $45 \%$ reported some improvement.

“... I did a lot of tests and had medicine. I could not move my left arm and left leg. There were no improvements in my movement during my hospital stay. I asked doctors and nurses about my recovery, they assured me I would be able to walk again. No one advised me or helped me to move. All of them told me to lie down on the bed and not move." (30-year-old male)

Stroke survivors were asked about the healthcare system in Bangladesh. 90\% had poor perceptions of the government health services however they were unable to identify how it could be improved. 10\% had a good experience using the healthcare system.

$$
\begin{aligned}
& \text { “... No one explained to me or my family what to do. } \\
& \text { I was just lying in bed. After a week they discharged } \\
& \text { me but they did not tell me what I needed to do next. } \\
& \text { I could not move the right side of my body and I had } \\
& \text { some problems speaking. I did not have any informa- } \\
& \text { tion about rehabilitation services after stroke. I did not } \\
& \text { even receive any therapy during my stay at hospital. If } \\
& \text { therapy services were available at hospital I could get } \\
& \text { more benefits. When the hospital discharged me, I went } \\
& \text { back to my home. I was just lying down at home as I did } \\
& \text { in hospital. One of my family friends suggested I go to } \\
& \text { CRP, but CRP was far from my home... A service near } \\
& \text { my home or in the community will definitely reduce my } \\
& \text { suffering and the cost.” (30-year-old male) }
\end{aligned}
$$

\section{THEME 3: ACCESS TO REHABILITATION FOLLOWING DISCHARGE FROM HOSPITAL}

The stroke survivors heard about CRP from varying sources, $45 \%$ were recommended CRP by relatives and $40 \%$ were referred by a doctor. The remaining $15 \%$ were encouraged to attend by friends and neighbours who had previously received treatment from CRP.

"On discharge, no one from the hospital told me about rehabilitation services. They told me to do some exercise at home. One of my relatives informed me that he knew someone who had been to CRP after their stroke. That patient received therapy and regained his mobility. He encouraged me to go to CRP for therapy." (35-year-old female)

All stroke survivors received physiotherapy intervention at CRP, with $60 \%$ receiving occupational therapy in addition to physiotherapy. 35\% received speech and language therapy alongside their physiotherapy and occupational therapy intervention.

"As I had problems with my mobility, managing daily activities and my speech, I received physiotherapy, occupational therapy and speech therapy. All therapies were useful, particularly physiotherapy, which helped me to walk again...” (52-year-old male)

\section{THEME 4: LEVEL OF INDEPENDENCE ONE YEAR POST DISCHARGE FROM CRP}

18 stroke survivors reported being able to transfer from lying to sitting independently and 14 reported independence with some activities of daily living. 8 reported that they could mobilise unaided and 4 reported improvements in their mood. 1 stroke survivor reported regaining movement only in his fingers and another reported no improvement in his function.

One stroke survivor describes the positive outcome following therapy: 
"I gained about $80 \%$ of my mobility back after receiving physiotherapy at CRP. When I went back to my community, I did my daily activities; I did my cooking, washing and some other activities. It was a new life for me. I did not believe I could walk again or do something for my family." (35-year-old female)

In contrast, another stroke survivor describes their negative experience:

"I was completely dependent on my family. I started my therapy at CRP 9 months after my stroke and I did not improve much. I always need someone to help me. At home my wife does everything. I was not able to go back to my job. I was not able to visit the nearby shop from my home. I felt like a prisoner. I could not go outside and meet people to speak to." (60-year-old male)

\section{THEME 5: CHALLENGES OF RETURNING HOME FOLLOWING REHABILITATION AT CRP}

All stroke survivors required some support from their caregivers. 80\% were unable to access safe and effective rehabilitation.

\begin{abstract}
"When I went home from CRP, I still needed therapy. Unfortunately, there was no facility for therapy in my community. In my nearby town there was a therapy centre and I went there only once. That centre was run by a non-qualified therapist. He was once a patient caregiver and claimed he had some short training. But he only treated me with some electrical devices. He used red light (Infrared Radiation)...” (45-year-old male)
\end{abstract}

$10 \%$ attended a private therapy centre for treatment.
"At the town in my district I found one therapy centre run by a physiotherapist. I went there several times. It was far from my home and travelling to that centre was very difficult. I could not use public transport comfort- ably. I needed to hire private transport, which was ex- pensive. The quality of the therapy service was satisfac- tory but not as good as CRP.” (52-year-old male)

The remaining $10 \%$ continued to stay near CRP and seek treatment.
"CRP discharged me from its regular therapy services but I did not go back to my home, as I could not walk. So what would I do if I went back to my home? I rented a house close to CRP and took extra therapy services from various therapy centres around CRP." (51-year-old female)

$70 \%$ of stroke survivors were unable to return to work or homemaking due to the physical, mental and social implications of their stroke.

"I was a housewife... Now I am useless. I am a burden on my family. My husband, son and daughter always spend time with me. Most days my daughter cannot go to her college. My husband is depressed. He already spent enough money on me. Now our financial situation is bad. I don't know if I will be able to work again or not. I am always thinking and depressed. What is the future of my family? I can't visit anywhere. No social activity. I have to depend on others to wash and bath me. This is so frustrating and humiliating." (30-yearold female)

The remaining $30 \%$ returned to work or homemaking.

"I am lucky that I recovered very well. Although it is not $100 \%$, I can do all of my work. Very occasionally I need help from someone. I have returned to my work. I work for a private company. If I could not go back to my job my family would be in big trouble. Now my son and daughter are able to continue their study." (52-year-old male)

All stroke survivors reported that their stroke had a negative impact on their household income.

"Continuing therapy is expensive. I spent all of my savings and borrowed some money. Therapy not provided by CRP is not satisfactory. But living around CRP and having therapy is expensive. In my community, no therapy service is available. If I had enough money I could continue my treatment here at CRP." (42-year-old male)

Other common challenges included social isolation and some communication difficulties.

"I am lonely because my wife and children have given up on me" (57-year-old male)

"I have some communication problems which has led to me losing money and having issues with socialising" (30-year-old female)

\section{THEME 6: THE CHALLENGES EXPERIENCED BY CAREGIVERS}

Caregivers were asked about the impact of their relative's stroke on their life. Common challenges included financial struggles and a lack of time for their social, educational and personal needs.

"My mum cannot do much for herself. I have to help her with her daily activities. I also need to cook, do washing and other activities for my family. I have little time for studying and to go to school. I have already dropped a year. I don't know what will happen next year." (16-year-old daughter)

\section{ANOTHER CAREGIVER DISCUSSED THE FOLLOWING FINANCIAL CHALLENGES}

"My father was the only member of our family earning. He ran a small shop. Since his stroke he has not able to go back to his job. He is not earning anymore. We have already spent all of our savings and borrowed money from our relatives. We don't have enough land or any other sources of income. I am in the middle of my study. I am not sure if I will get a job or not. I also need to spend a lot of time with my father. My mother's health is also not good. So I always feel helpless." (22-year-old son)

When asked about how their health had been affected, only $10 \%$ of caregivers no physical problems. $55 \%$ of caregivers had developed back pain with a further $25 \%$ reporting neck pain from caring for their relative. $10 \%$ of caregivers reported upper limb paraesthesia. 
"My husband is dependent on me... I need to give a lot of physical effort. I am always busy doing something. I have very little time for rest. Initially I did not know how to move my husband, I use a lot of effort to move him. Now I have developed pain in my back. I am not feeling well. I have no rest in the day. I cannot sleep well as my husband wakes up in the middle of the night, so I have to wake up as well.” (42-year-old wife)

Most caregivers were unsure how the healthcare system could be improved. However, some felt that more preventative and rehabilitative programmes should be more easily accessible for caregivers and government hospitals should provide therapy.

\begin{abstract}
“... Two of my family members are always busy with my patient. Actually, we cannot do any other work. If therapy services were available in my Sub District Hospital or in the community it would be good for us. Therapy services must be provided in government hospitals then we can get this service for free or low cost. Private therapy services are expensive.” (27-year-old male)
\end{abstract}

\section{DISCUSSION}

Our study found that knowledge of stroke and its associated risk factors amongst participants was poor prior to their stroke. With such poor awareness of the risk factors associated with stroke, it is likely that very few understand the importance of seeking medical advice to manage any modifiable risk factors. Stroke mortality is higher in Asia when compared to Western Europe, the Americas and Australasia. ${ }^{15}$ Many of these strokes could be preventable if awareness is improved and these risk factors are better managed.

Research has found the use of mass media and public education campaigns are effective in increasing awareness of stroke and its risk factors. ${ }^{16,17}$ Previously, there have been various barriers that may have affected how easy it was to disseminate information via media sources in Bangladesh including low literacy levels ${ }^{18,19}$ and difficulty accessing internet in rural areas. ${ }^{20}$ As these barriers reduce, it is vital that the government and health professionals work closely to educate the public to reduce this growing epidemic. ${ }^{4}$

Despite a varying LOS, none of our stroke survivors received any form of rehabilitation during their acute hospital admission. A Cochrane review found that patients with acute stroke who receive multidisciplinary rehabilitation were more likely to survive, regain independence and return home. ${ }^{21}$ Stroke guidelines have emphasised the importance of early multidisciplinary assessment and rehabilitation, ${ }^{22,23}$ which is associated with greater functional outcomes on discharge and follow-up ${ }^{24}$ and a shorter hospital LOS. ${ }^{25}$ The lack of advice and rehabilitation in hospital contributed to the stroke survivors' poor satisfaction level with the healthcare system in our study.

Other factors delaying the initiation of rehabilitation included inconsistent advice, a low rate of onward referrals from medical professionals (40\%) and an absence of pathways linking stroke survivors into rehabilitation facilities. Studies have found that significant improvements were made in rehabilitation in the first 3 months following a stroke, with the recovery rate decreasing between 3 and 6 months. ${ }^{26,27}$ This is illustrated in our study as a stroke survivor who did not receive any rehabilitation until 9 months post-stroke reported minimal improvements in his function following rehabilitation. In addition, these delays result in an increased risk of secondary complications occurring in the absence of therapy intervention. ${ }^{28}$

The common challenges in our study experienced by stroke survivors were financial issues, social isolation and difficulties walking which is consistent with previous research.5,29,30 Returning to work was another challenge identified in our study. Previous research has shown that it is influenced by the ability to walk, cognitive function and occupation and is associated with improved satisfaction with life. ${ }^{31}$ Therefore, return to work schemes should be included within rehabilitation. ${ }^{32}$ Despite $40 \%$ reporting independent mobility and $70 \%$ reporting independence with some daily activities, only $30 \%$ of stroke survivors in our study returned to work. This may be the result of a lack of ongoing community rehabilitation in Bangladesh. ${ }^{33}$ Moreover, the lack of governing bodies for professions such as physiotherapy leaves stroke survivors seeking ineffective and unsafe treatment from unqualified and unregulated therapists. ${ }^{33}$

Challenges faced by the caregivers in this study included financial struggles and a lack of time for their social, educational and personal needs. For example, one young caregiver had no time for her education. Although caregiving can improve carers' self-efficacy, enable them to learn new skills and strengthen family relationships, it often results in chronic stress, which has a negative impact on the caregivers' physical and psychosocial health. ${ }^{11}$ With no government care homes or support for informal carers, ${ }^{34}$ we found that the responsibility of supporting the stroke survivor may have forced a shift in the relationship between caregiver and stroke survivor, with one caregiver referring to their affected family member as "my patient”. Considerable changes in family roles and responsibilities were also identified by family caregivers in Sri Lanka ${ }^{35}$ and India, 36 with their lifestyles being significantly altered in an unfavourable way. ${ }^{35}$ These studies also recognised the need for better provision of caregiver education and support, which is consistent with our findings.

Back and neck pain were the most common physical complaints for caregivers in our study. This indicates the need for further support through preventative and rehabilitative training, which was identified by caregivers in this study to improve the healthcare system. Research suggests that this should be in the form of psychosocial interventions to improve skills such as problem solving and stress coping $^{36}$ as well as practical nursing training to reduce caregiver burden. ${ }^{10}$

There were several limitations to this study. Despite the small sample size in our study, our findings are supported by recent studies in Sri Lanka ${ }^{35}$ and India, ${ }^{37}$ which have investigated similar topics. Unmet community rehabilitation needs were identified akin to those in Bangladesh, with affordability and availability limiting access to rehabilitation. ${ }^{35,37}$ Although the value of qualitative research is well recognised, 38 due to the translation from Bengali into English, it could have resulted in slight misinterpretation of the participants. Our population is not representative of those 
who did not receive any rehabilitation due to the absence of a care pathway to identify stroke survivors. As the interviewer was a student physiotherapist affiliated with CRP, there was potential for professional bias to occur. Lastly, this was a single-centred study based near Dhaka, the capital of Bangladesh. This may have accounted for the high prevalence of educated and employed participants, reducing the generalisation of our findings across Bangladesh.

\section{CONCLUSIONS}

The awareness of stroke and its risk factors was poor. The government and healthcare professionals need to improve education about this topic to increase awareness and reduce the incidence of stroke.

No participants received rehabilitation during their hospital stay and all experienced delays in accessing rehabilitation upon discharge. Implementation of a stroke pathway that increases awareness and onward referrals to rehabilitation may improve access and reduce these delays. Thus, improving possible outcomes for stroke survivors and reducing caregiver burden.

Both stroke survivors and caregivers experienced socioeconomic, psychological and physical strains therefore ongoing support and training should be available to reduce these burdens.

Most stroke survivors did not return to work. Future research should investigate this issue and the experiences of stroke survivors and caregivers who did not receive rehabilitation. This would help identify areas for development in healthcare and rehabilitation, whilst working towards Bangladesh achieving its Sustainable Development Goals.

\section{ACKNOWLEDGEMENTS}

We would like to acknowledge CRP and the participants for their involvement and Dr. Dorine van Ravensberg for her valuable suggestions.

\section{FUNDING}

No funding was received.

\section{CONFLICT OF INTEREST}

The authors completed the Unified Competing Interest form at http://www.icmje.org/coi disclosure.pdf (available upon request from the corresponding author), and declare no conflicts of interest.

\section{CORRESPONDENCE TO:}

Miss Emma Clare Garrett-Jones

Guest faculty at Bangladesh Health Professions Institute (BHPI)

Centre for the Rehabilitation of the Paralysed (CRP)

Savar, Dhaka 1343

Bangladesh

emmagarrettjones@gmail.com

Mr Echezona Anthony Anakor

Guest faculty at Bangladesh Health Professions Institute (BHPI)

Centre for the Rehabilitation of the Paralysed (CRP)

Savar, Dhaka 1343

Bangladesh

e.anakor@gmail.com 


\section{REFERENCES}

1. Lozano R, Naghavi M, Foreman K, et al. Global and regional mortality from 235 causes of death for 20 age groups in 1990 and 2010: a systematic analysis for the Global Burden of Disease Study 2010. Lancet. 2012;380(9859):2095-2128. doi:10.1016/s0140-6736(1 2)61728-0

2. Murray CJL, Vos T, Lozano R, et al. Disabilityadjusted life years (DALYs) for 291 diseases and injuries in 21 regions, 1990-2010: a systematic analysis for the Global Burden of Disease Study 2010. Lancet. 2012;380(9859):2197-2223. doi:10.1016/s014 0-6736(12)61689-4

3. Feigin VL, Norrving B, Mensah GA. Global Burden of Stroke. Circ Res. 2017;120(3):439-448. doi:10.1161/ circresaha.116.308413

4. Venketasubramanian N, Yoon BW, Pandian J, Navarro JC. Stroke Epidemiology in South, East, and South-East Asia: A Review. J Stroke. 2017;19(3):286-294. doi:10.5853/jos.2017.00234

5. Walsh ME, Galvin R, Loughnane C, Macey C, Horgan NF. Community Re-integration and longterm need in the first five years after stroke: results from a national survey. Disabil Rehabil. 2014;37(20):1834-1838. doi:10.3109/09638288.2014.9 $\underline{81302}$

6. Srivastava A, Taly AB, Gupta A, Murali T. Poststroke depression: Prevalence and relationship with disability in chronic stroke survivors. Ann Indian Acad Neurol. 2010;13(2):123-127. doi:10.4103/0972-2327.6 $\underline{4643}$

7. Sturm JW, Donnan GA, Dewey HM, Macdonell RAL, Gilligan AK, Thrift AG. Determinants of handicap after stroke: the North East Melbourne Stroke Incidence Study (NEMESIS). Stroke. 2004;35(3):715-720. doi:10.1161/01.str.0000117573.1 9022.66

8. Chau JPC, Thompson DR, Twinn S, Chang AM, Woo J. Determinants of participation restriction among community dwelling stroke survivors: A path analysis. BMC Neurol. 2009;9(1):49. doi:10.1186/147 1-2377-9-49

9. Mayo NE, Wood-Dauphinee S, Côté R, Durcan L, Carlton J. Activity, participation, and quality of life 6 months poststroke. Arch Phys Med. 2002;83(8):1035-1042. doi:10.1053/apmr.2002.33984
10. Bhattacharjee M, Dalal P, Gawali K, Vairale J. Factors affecting burden on caregivers of stroke survivors: Population-based study in Mumbai (India). Ann Indian Acad Neurol. 2012;15(2):113-119. doi:10.4 103/0972-2327.94994

11. Schulz R, Sherwood PR. Physical and mental health effects of family caregiving. Am J Nurs. 2008;108:23-27. doi:10.1097/01.naj.0000336406.4524 $\underline{8.4 \mathrm{C}}$

12. Pinquart M, Sörensen S. Differences between caregivers and noncaregivers in psychological health and physical health: A meta-analysis. Psychol Aging. 2003;18(2):250-267. doi:10.1037/0882-7974.18.2.250

13. Mamin FA, Islam MS, Rumana FS, Faruqui F. Profile of stroke patients treated at a rehabilitation centre in Bangladesh. BMC Res Notes. 2017;10:520. do i:10.1186/s13104-017-2844-X

14. Islam MN, Moniruzzaman M, Khalil MI, et al. Burden of stroke in Bangladesh. Int J Stroke. 2013;8(3):211-213. doi:10.1111/j.1747-4949.2012.008 85.x

15. Feigin VL, Forouzanfar MH, Krishnamurthi R, et al. Global and regional burden of stroke during 1990-2010: findings from the Global Burden of Disease Study 2010. Lancet. 2014;383(9913):245-255. doi:10.1016/s0140-6736(13)61953-4

16. $\mathrm{Mu}$ “ ller-Nordhorn J, Nolte $\mathrm{CH}$, Rossnagel K, et al. Knowledge about risk factors for stroke. A population-based survey with 28090 participants. Stroke. 2006;37(4):946-950. doi:10.1161/01.str.000020 $\underline{9332.96513 .82}$

17. Becker KJ, Fruin MS, Gooding TD, Tirschwell DL, Love PJ, Mankowski TM. Community-based education improves stroke knowledge. Cerebrovasc Dis. 2001;11(1):34-43. doi:10.1159/000047609

18. UN Educational, Scientific and Cultural Organisation (UNESCO), Bangladesh Bureau of Statistics. Literacy assessment survey 2008. Accessed December 23, 2018. http://www.un-bd.org/Docs/Publi cation/Bangladesh_Literacy_Assessment_Survey 200 $\underline{8 . P d f}$

19. UN Educational, Scientific and Cultural Organisation (UNESCO). Bangladesh: Education and Literacy. Accessed January 21, 2019. http://uis.unesc o.org/en/country/bd?theme=education-and-literacy/ 
20. Islam A, Hoq KMG. Community internet access in rural areas: A study on Community Information Centres in Bangladesh. Malays J Libr Inf Sci. 2010;15:109-124.

21. Stroke Unit Trialists' Collaboration. Organised inpatient (stroke unit) care for stroke. Cochrane Database Syst Rev. Published online 2013. doi:10.100 2/14651858.CD000197.pub2/full

22. National Institute for Health and Care Excellence. Stroke rehabilitation in adults. Published 2013. Accessed October 19, 2018. https://www.nice.org.uk/g uidance/cg162/resources/cg162-stroke-rehabilitatio n-full-guideline 3

23. Hebert D, Lindsay MP, McIntyre A, et al. Canadian stroke best practice recommendations: Stroke rehabilitation practice guidelines, update 2015. Int J Stroke. 2016;11(4):459-484. doi:10.1177/17474930166 $\underline{43553}$

24. Cifu DX, Stewart DG. factors affecting functional Outcome After Stroke: A critical review of rehabilitation interventions. Arch Phys Med Rehabil. 1999;80(5):S35-S39. doi:10.1016/s0003-9993(99)9010 $\underline{1-6}$

25. Salter K, Jutai J, Hartley M, et al. Impact of early vs delayed admission to rehabilitation on functional outcomes in persons with stroke. J Rehabil Med. 2006;38(2):113-117. doi:10.1080/16501970500314350

26. Verheyden G, Nieuwboer A, De Wit L, et al. Time course of trunk, arm, leg, and functional recovery after ischemic stroke. Neurorehabil Neural Repair. 2007;22(2):173-179. doi:10.1177/1545968307305456

27. Lee KB, Lim SH, Kim KH, et al. Six-month functional recovery of stroke patients: a multi-timepoint study. Int J Rehabil Res. 2015;38(2):173-180. do i: $10.1097 / \mathrm{mrr} .0000000000000108$

28. Brandstater ME, Shutter LA. Rehabilitation Interventions During Acute Care of Stroke Patients. Top Stroke Rehabil. 2002;9(2):48-56. doi:10.1310/yga x-x5vk-nhvd-hgpa
29. Daniel K, Wolfe CDA, Busch MA, McKevitt C. What are the social consequences of stroke for workingaged adults? A systematic review. Stroke. 2009;40(6):e431-40. doi:10.1161/strokeaha.108.53448 $\underline{7}$

30. Mishra A, Mishra N, Gajjar K. Financial burden of stroke on family and caregiver in India: a literature review. Int J Res Med Sci. 2016;4:3675-3678. doi:10.18 203/2320-6012.ijrms20162900

31. Vestling M, Tufvesson B, Iwarsson S. Indicators for return to work after stroke and the importance of work for subjective well-being and life satisfaction. $J$ Rehabil Med. 2003;35(3):127-131. doi:10.1080/165019 $\underline{70310010475}$

32. Wolfenden B, Grace M. Returning to work after stroke: a review. Int J Rehabil Res. 2009;32(2):93-97. d oi:10.1097/mrr.0b013e328325a358

33. Mamin FA, Hayes R. Physiotherapy in Bangladesh: Inequality Begets Inequality. Front Public Health. 2018;6:80. doi:10.3389/fpubh.2018.00080

34. World Health Organisation. Bangladesh Health System Review. Accessed October 26, 2018. https://iri s.wpro.who.int/bitstream/handle/10665.1/11357/9789 290617051_eng.pdf

35. Wagachchige Muthucumarana M, Samarasinghe $\mathrm{K}$, Elgán C. Caring for stroke survivors: experiences of family caregivers in Sri Lanka - a qualitative study. Top Stroke Rehabil. 2018;25:397-402. doi:10.1080/107 $\underline{49357.2018 .1481353}$

36. Cheng HY, Chair SY, Chau JPC. The effectiveness of psychosocial interventions for stroke family caregivers and stroke survivors: A systematic review and meta-analysis. Patient Educ Couns. 2014;95(1):30-44. doi:10.1016/i.pec.2014.01.005

37. Kamalakannan S, Venkata MG, Prost A, et al. Rehabilitation needs of stroke survivors after discharge from hospital in India. Arch Phys Med Rehabil. 2016;97(9):1526-1532.e9. doi:10.1016/j.apm r.2016.02.008

38. Fitzpatrick R, Boulton M. Qualitative methods for assessing health care. Qual Health Care. 1994;3(2):107-113. doi:10.1136/qshc.3.2.107 